\title{
The new EU regulation on nutrition and health claims: comments related to experiences from the Swedish Code of Practice
}

\author{
Susanne Bryngelsson and Nils-Georg Asp
}

SNF Swedish Nutrition Foundation, Lund, Sweden

Abstract

The new European Union (EU) regulation on nutrition and health claims came into force on 19 January 2007. This means that the same rules for use of such claims in advertisements, labelling and presentation of foods, including food supplements, will now be implemented throughout the EU. Some countries have had Codes of Practices allowing certain health claims. Experiences from such Codes, such as in Sweden since 1990, will be useful in implementing the new regulation. When used in a responsible way according to the regulation, health claims may be important in driving product development and assisting consumers in making healthy choices.

\section{Introduction}

$\mathrm{T}$ he new regulation of the European Parliament and of the Council on nutrition and health claims made on foods (EC no. 1924/ 2006 by 20 December 2006) came into force on 19 January 2007, to be implemented by 1 July 2007 (1). The regulation covers all foods, including food supplements and foodstuffs for particular nutritional uses, and concerns nutrition and health claims in advertisements, labelling and presentation of foods towards consumers, as well as in restaurants, hospitals and schools, etc.

\section{Community register of allowed claims}

The European Commission will establish a Community Register for all health claims for which an application has been submitted (Article 20). A summary of the application will be made public, as well as the outcome - positive or negative - of the evaluation. Only claims in the Register that have been subject to evaluation with a positive outcome will be allowed (Article 10). Vague or generally worded claims will be allowed only if accompanied by a claim according to the Register. It is not allowed to claim that health can be affected negatively by not consuming the product. Claims with reference to a single physician or other expert within the field of nutrition are also not allowed.

When using health claims, the importance of a varied and balanced diet and a healthy lifestyle shall be stated (Article 10), as well as the intake necessary to obtain the claimed effect.

\section{Categories of health claims}

The regulation defines health claims as "any claim that states, suggests or implies that a relationship exists between a food category, a food or one of its constituents and health". The two principal categories of health claims are:

- reduction of disease risk claims and claims referring to children's development and health (Article 14).

- claims other than those referring to the reduction of disease risk and children's development and health (Article 13).

Three different types of Article 13 claims are defined, i.e. health claims describing or referring to (a) the role of a nutrient or other substance in growth, development and the functions of the body, (b) psychological and behavioural functions, and (c) slimming or weight control or reduction in the sense 
of hunger or an increase in the sense of satiety or to reduction of the available energy from the diet.

\section{Article 13 claims}

A first action within the new regulation will be to establish a list of generic claims according to Article 13. The competent authorities (CAs) of the 27 member states will have the opportunity to suggest such claims, incl. well-established functions of nutrients and other substances within 1 year. The list will then be established by the Commission before 31 January 2010, after consultations with the European Food Safety Authority (EFSA).

Regarding claims based on new scientific evidence, and/or proprietary data for which protection is requested, applications shall be submitted to the national CA, which will send it further to EFSA for their opinion (Article 18). The Commission makes the final decision to include the new claim in the Article 13 list.

\section{Article 14 claims}

All claims related to reduction of disease risk and referring to children's development and health require an application to the national $\mathrm{CA}$ for evaluation by EFSA and final decision by the Commission after a specific committee procedure (Articles 15-17, 19). As for Article 13 claims, the Article 14 claims can be based on either generally recognized scientific data or new and/or protected data.

When using reduction of disease risk claims according to Article 14, there is a specific requirement to mention the fact that the disease to which the claim is referring has multiple risk factors and that altering one of them may or may not have a beneficial effect.

\section{Nutrient profiles}

By 19 January 2009 the Commission will establish specific nutrient profiles for foods bearing nutrition or health claims. The nutrient profiles will be established considering particularly the content of certain nutrients such as fat, saturated fatty acids, trans fatty acids, sugars and salt/sodium, and the role and importance of the food in the diet for various groups. The profiles shall be set after consultations with interested parties, in particular food business operators and consumer groups.
The Swedish Code of Practice on health claims Since 1990, it has been possible to use certain health claims in Sweden within the Food Sector's Code of Practice "Health claims in the labelling and marketing of food products" (2). This Code was established in close collaboration with the Swedish CAs. The principals of the Code are the Swedish Food Federation and the Swedish Federation of Food Retailers. Swedish Nutrition Foundation (SNF) has a co-ordinating and advisory role within the Code.

Since the start, the Swedish Code has listed eight well-established diet-health relationships, closely reflecting the official nutrition recommendations, around which generic claims in two steps can be made. A ninth relationship, between wholegrain consumption and (coronary) heart disease, was added in 2003. The reduction of disease risk claims allowed according to the Code will be applied for under Article 14. However, the possibility of rewording them in terms of maintaining health will also be suggested as Article 13 claims, e.g. "helps to maintain a healthy heart" instead of "helps to reduce the risk of coronary heart disease".

Nutrient function claims around well-established functions of nutrients are also allowed according to the Swedish Code. Examples are provided, but not any exhaustive list.

In 2001, the possibility of using "product-specific physiological claims" (abbreviated PFP in Swedish) was added in the Swedish Code. A basic requirement is that such claims have been substantiated in human intervention studies using the product as normally consumed. Premarketing expert evaluation of these studies is required, and the expert report is made public on the homepage of the Code (www.hp-info.nu). Expert evaluations have been organized by SNF. The approved product-specific physiological claims would seem to fit best under Article 13.5 in the EU regulation.

The level of scientific substantiation that has been required for approval of PFP is concordant with the criteria specified by the PASSCLAIM project (3). Experiences from the Swedish Code emphasize the importance of using a study population representative of the intended consumer and characterization of the background diet. Furthermore, the study duration should be adequate with respect to the effect studied and claim applied for. When an ingredient is used in different food matrices, possible effects of the matrix itself have to be considered. 
Nutrient profiles have been applied since the start of the Swedish Code, expressed in general terms in the first versions. In the most recent version of the Code dated September 2004 (2), nutrient profiles have been elaborated and reference is made to the criteria for using the official keyhole symbol when applicable (4). Thus, the controversial question of nutrient profiles has not been an issue regarding the Swedish Code.

\section{Concluding comments}

The Swedish Code of Practice is well in line with the new EU regulation on nutrition and health claims, although with somewhat different categorization of different claims. In particular, the Swedish Code makes explicit differentiation between "generic" and "product-specific" claims. The former type of claims can be used by all products fulfilling the compositional criteria, whereas intervention studies with the products and premarketing evaluation of these studies are required for product-specific claims.

SNF and the Swedish Food Federation have been invited to assist the Swedish CA, the National Food Administration, with suggestions for well-established generic Article 13 claims. Such suggestions will be made considering the general requirements of the Code that claims should be not only scientifically true but also meaningful to the intended consumers, i.e. primarily claims based on and concordant with official nutrition recommendations. Generic claims are important since they are applicable to a range of products, provide opportunities for small and medium-sized enterprises, and therefore contribute towards driving product development. If limited to claims meaningful for the consumer they may be useful for individuals looking for healthier food choices, and could contribute towards improved public health in the long term.

\section{References}

1. Corrigendum to Regulation (EC) 1924/2006 of the European Parliament and of the Council of 20 December 2006 on nutrition and health claims made on foods. Official Journal of the European Union L 404, 30 December 2006 (http://eur-lex.europa.eu/LexUriServ/ site/en/oj/2007/1_012/1_01220070118en00030018.pdf)

2. Anon. Health claims in the labelling and marketing of food products. The food sector's Code of Practice. September 2004 (http://www.hp-info.nu/SweCode_2004_ 1.pdf)

3. Aggett PJ, Antoine J-M, Asp N-G, Bellisle F, Contor L, Cummings $\mathrm{JH}$, et al. PASSCLAIM process for the assessment of scientific support for claims on foods, consensus on criteria. Eur J Nutr 2005; 44: I/1-30.

4. Anon. National Food Administration's regulations on the use of a particular symbol. LIVSFS 2005:9.

\section{Susanne Bryngelsson}

SNF Swedish Nutrition Foundation

Ideon Science Park

SE-223 70

Lund

Sweden 